\title{
Microscopía de barrido de efecto túnel: ojos y dedos para nano
}

\author{
María Bassiouk* y Vladimir A. Basiuk**
}

\section{DESCUBRIMIENTO Y PRINCIPIOS}

Mientras que la microscopía en general juega un papel crucial en el desarrollo científico al revelar detalles, inalcanzables para el ojo humano, acerca de la estructura y función de diversos componentes de nuestro entorno, la microscopía de barrido de efecto túnel (STM por sus siglas en inglés) es indudablemente una de sus variantes más fascinantes. La técnica de STM es capaz de producir imágenes con resolución atómica de las superficies analizadas, permitiendo obtener información detallada acerca de su estructura química. Además, puesto que las imágenes se obtienen en tiempo real, es posible estudiar procesos moleculares que se llevan a cabo in situ en la superficie de la muestra, registrando las diferentes etapas del proceso. Por otro lado, la técnica de STM puede permitir la manipulación de moléculas y átomos individuales con precisión nanométrica gracias a las interacciones entre la punta y la muestra. Todas estas posibilidades hacen de la STM una herramienta de gran utilidad e importancia para la nanociencia y la nanotecnología, sirviendo como los "ojos" que observan las estructuras de interés, y los "dedos" que las manipulan. El STM fue desarrollado por Gerd Binnig y Heinrich Rohrer en 1981 en el laboratorio de IBM Zürich en Rüschlikon, Suiza [1]. Por esta invención, ambos investigadores se hicieron acreedores al Premio Nobel en Física en 1986.

Antes de revisar algunos ejemplos de las sorprendentes aplicaciones del STM, veamos brevemente los principios fundamentales de la técnica (fig. 1a). En el STM una punta metálica muy aguda se aproxima a una muestra eléctricamente conductora a una distancia tan cercana como $1 \mathrm{~nm}$ y se aplica un pequeño voltaje de aproximadamente $0.1 \mathrm{~V}$ entre ambas. Esta proximidad y diferencia de potencial hacen que los electrones fluyan de la punta a la muestra (o viceversa, dependiendo de la polaridad del voltaje), logrando atravesar la barrera que representa el espacio entre ambas, y produciéndose el fenómeno de mecánica cuántica conocido como corriente de túnel. La corriente de túnel depende exponencialmente de la distancia entre la punta y la muestra; de esta forma, para una corriente de túnel de alrededor de $1 \mathrm{nA}$ un cambio de $0.1 \mathrm{~nm}$ en esta distancia cambiaría la corriente por un factor de 10. Esta de-

\footnotetext{
* Estudiante de doctorado en ciencias bioquímicas de la UNAM. Autora/coautora de 5 artículos en revistas internacionales.

** Investigador Titular y jefe del Departamento de Química de Radiaciones y Radioquímica del Instituto de Ciencias Nucleares, UNAM. Editor en jefe de la revista Journal of Advanced Microscopy Research (American Scientific Publishers) y editor asociado de la Journal of Nanoscience and Nanotechnology (misma casa editorial). Autor/coautor de más de 160 artículos en revistas internacionales; editor de cuatro libros, incluyendo Chemistry of carbon nanotubes en tres tomos. E-mail: basiuk@nucleares.unam.mx. Los autores agradecen el apoyo para su investigación a través del proyecto UNAM DGAPA-IN100610. M. B. agradece el apoyo del Posgrado de Ciencias Bioquímicas de la UNAM, así como la beca para estudios de doctorado del Consejo Nacional de Ciencia y Tecnología (Conacyt).
} 
pendencia le confiere al STM sensibilidad en escala atómica [2]. Para este propósito, una buena resolución en el STM se considera de $0.1 \mathrm{~nm}$ lateral y $0.01 \mathrm{~nm}$ de profundidad. Una vez que comienza el flujo de la corriente de túnel, la punta barre la superficie de la muestra con la ayuda de un escáner fabricado de cerámica piezoeléctrica que se comprime y expande con precisión nanométrica, con base en el voltaje aplicado. Esta cerámica puede controlar los movimientos ya sea de la punta o de la muestra, dependiendo de la estructura de cada equipo de STM en particular. El movimiento se realiza en direcciones X, Y y Z, controlado por diferentes señales de voltaje. X y Y son movimientos sobre la superficie de la muestra, y $\mathrm{Z}$ es el movimiento de la distancia punta-muestra. Una red de retroalimentación coordina la corriente de túnel y la posición de la punta, de forma que la punta sigue la superficie de la muestra, mientras se registran las variaciones en $\mathrm{Z}$ necesarias para mantener la corriente de túnel constante como función de la posición en el plano X-Y. Estas variaciones en Z dependen de la densidad de estados en la superficie de la muestra, y de su relieve. Como resultado, se obtiene un conjunto de perfiles, ensamblados en una imagen que representa la estructura electrónica de la superficie, traducida en su topografía. La topografía se representa mediante una escala de color, cuya intensidad indica la altura del relieve [3]. Esta modalidad del STM se denomina corriente constante, es la más común y se utiliza para muestras con relieve marcado. Otra posible modalidad del STM es la de altura constante, en que se registran los cambios en la corriente de túnel necesarios para mantener constante la distancia punta-muestra; sin embargo, se utiliza con poca frecuencia ya que requiere de la muestra ser atómicamente plana.

Además de la precisión nanométrica, el STM presenta varias otras ventajas. Por ejemplo, existe la posibilidad de operación en distintos ambientes como aire, vacío, diversos gases y solución, así como temperaturas bajas o altas; todo esto permite adaptar las condiciones de análisis de acuerdo con la naturaleza del material de interés, y demás criterios importantes en cada estudio particular. Una gran ventaja adicional es que el STM no es destructivo para moléculas orgánicas, permitiendo conservar sus valiosas propiedades intrínsecas durante el análisis.

Los componentes esenciales de un equipo de STM incluyen una punta muy aguda, un portapuntas, un sustrato conductor, un portamuestras, un escáner controlado por un piezoeléctrico, un sistema de aislamiento antivibratorio, una computadora con el software necesario para controlar distintos parámetros del barrido y registrar, integrar y traducir la información obtenida, así como un conjunto de electrónicos para la comunicación entre el software y el mecanismo que realiza el barrido. La punta puede ser de materiales como tungsteno (W) o platino/iridio (Pt/Ir), entre otros, y, para lograr la mejor resolución posible, debe terminar en un solo átomo. Las puntas de Pt/Ir se usan principalmente para la operación en aire por su resistencia a la oxidación. El afilamiento de la punta se puede realizar por métodos físicos ó químicos, dependiendo del material y de la resolución buscada. El material a analizar se debe depositar sobre un sustrato conductor, limpio y de superficie plana, que puede ser por ejemplo el oro $\mathrm{Au}(111)$ o grafito pirolítico altamente ordenado (HOPG por sus siglas en inglés), este último siendo el más frecuentemente utilizado gracias a la facilidad de limpiar su superficie. Como se había mencionado, en principio, el STM puede operar en distintas condiciones; sin embargo, estas posibilidades dependen de la estructura del equipo del que se dispone.

La aplicación más frecuente del STM es la caracterización a nanoescala de las propiedades estructurales, químicas y electrónicas de diversos átomos y moléculas. No 
obstante, la técnica recientemente se ha comenzado a utilizar para la manipulación en escala nanométrica o nanomanipulación de átomos y moléculas pequeñas sobre superficies sólidas. La nanomanipulación aprovecha la interacción entre la punta y la muestra para realizar el rearreglo inducido y controlado de los materiales depositados sobre el sustrato. La estrecha dependencia entre la distancia punta-muestra y la intensidad de la corriente de túnel permite ya sea incrementar o disminuir la interacción entre la punta y la muestra, posibilitando realizar la manipulación y después observar el resultado. La nanomanipulación por STM puede ser vertical o lateral. En la nanomanipulación vertical (fig. 1b) se utilizan cambios controlados en el voltaje

FIGURA 1. Mecanismo general del STM en modo de corriente constante (a); y nanomanipulación (b) vertical y (c) lateral por medio de la punta del STM. (a) En el STM una punta metálica muy aguda se acerca a una muestra eléctricamente conductora a una distancia de aprox. $1 \mathrm{~nm}$ aplicando un pequeño voltaje entre ambas, para que se produzca el flujo de la corriente de túnel. La punta barre la superficie de la muestra por medio de un escáner piezoeléctrico en direcciones $X, Y$ y Z. Un conjunto de electrónicos de retroalimentación coordinan la corriente de túnel y la posición de la punta, para que ésta siga la superficie de la muestra, mientras se registran las variaciones en $\mathrm{Z}$ necesarias para mantener la corriente de túnel constante. Se obtiene un conjunto de perfiles ensamblados en una imagen que representa la estructura electrónica de la superficie, traducida en su topografía. La nanomanipulación aprovecha la interacción entre la punta y la muestra para reacomodar átomos o moléculas depositadas sobre un sustrato, y puede ser vertical (b) o lateral (c). En la vertical (b), la punta se acerca a la molécula de interés y se utilizan cambios controlados en el voltaje para primero transferir a la molécula de la muestra a la punta, llevarla a su nueva ubicación, y transferirla nuevamente al sustrato. En una variante de nanomanipulación lateral (c), se aprovecha el efecto de atracción entre la punta y la molécula de interés para empujarla lentamente siguiendo la trayectoria de la punta hacia su nueva ubicación sobre el sustrato.
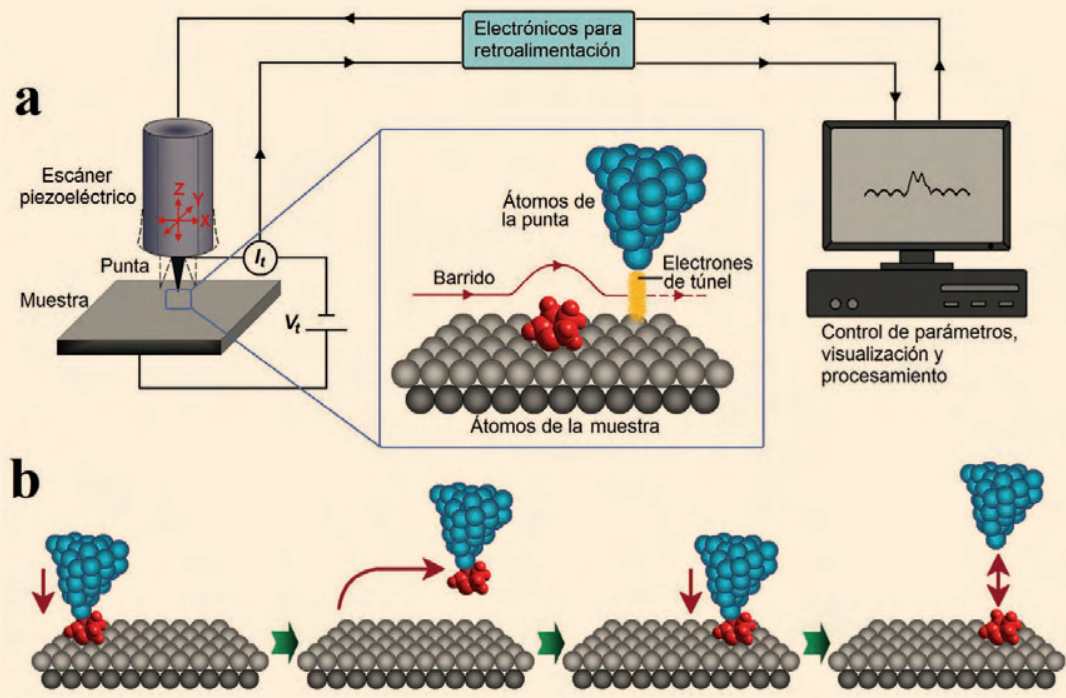

c

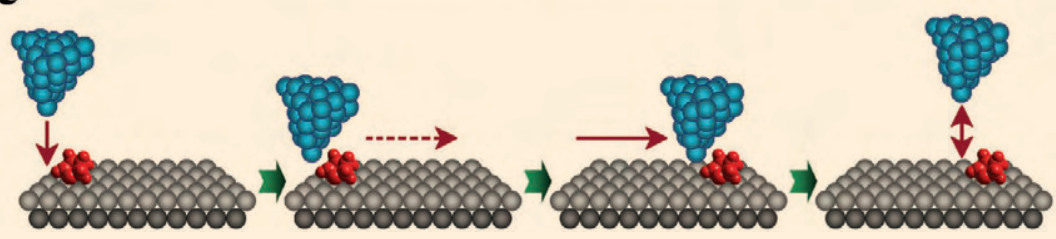


para transferir el átomo/molécula manipulada de la muestra a la punta o viceversa. De esta forma, es posible primero acercar la punta al material de interés, levantarlo, transferirlo hacia otro sitio, y volver a colocarlo sobre el sustrato. En la nanomanipulación lateral se utiliza la interacción punta-muestra para desplazar al átomo o molécula adsorbida en la superficie de la muestra, aprovechando los efectos de repulsión y de atracción entre ambos. El efecto de repulsión se puede emplear para producir un "salto" del átomo/molécula a un sitio vecino para alejarse de la punta. El efecto de atracción se puede emplear también para producir un "salto" del átomo/molécula pero en este caso desde un sitio vecino hacia la punta, o también para arrastrar o empujar lentamente al átomo/molécula siguiendo la trayectoria de la punta (ejemplo ilustrado en la figura 1c). La elección del tipo de nanomanipulación entre la vertical o algún modo de la lateral depende de la naturaleza química del átomo/molécula de interés, sustrato, punta, así como de la distancia buscada para el desplazamiento ([4] y referencias de ahí).

\section{EQUIPOS COMERCIALES}

Actualmente, se fabrican diversos equipos de STM comerciales de distintos alcances, niveles de sofisticación y costos. También existe la posibilidad de fabricación de equipos "caseros" improvisados que pueden resultar más económicos; aun así, es indispensable contar con todos los componentes esenciales tanto como con un nivel de conocimiento que permita ensamblar adecuadamente dichos componentes para producir un equipo de STM funcional. Una posibilidad adicional es añadir componentes caseros a un equipo comercial, dependiendo de las necesidades.

Dentro de los equipos comerciales, se pueden encontrar desde dispositivos sencillos, compactos, económicos, fáciles en su manejo y portátiles, hasta aparatos muy sofisticados, costosos y de alto alcance, cuyo manejo requiere de un conocimiento profundo, destreza, y condiciones de trabajo muy específicas para explotar todas las posibilidades que ofrecen.

Veamos un ejemplo de un equipo comercial sencillo, el Nanosurf easyScan E-STM (fig. 2a). Este equipo es portátil, compacto, económico y de fácil manejo. Consta de una cabeza que contiene a la punta fijada en una plataforma conectada a tres piezo-cristales X, Y y Z, el portamuestras en que se coloca el sustrato con el material a analizar, y una cubierta transparente que protege a los componentes anteriores. La cabeza se encuentra montada sobre una base antivibratoria, y conectada a una caja que contiene a todos los electrónicos que, a su vez, se conecta por medio de una serie de cables a una computadora en que se ha instalado el software provisto junto con el equipo [5]. A pesar de que este ensamble de componentes esenciales del STM es quizá el más minimalista posible, la modestia de este equipo no le impide producir imágenes con resolución atómica de diversos materiales. Las principales limitaciones de este equipo incluyen que únicamente puede operar en condiciones ambientales (en cuanto a temperatura y presión), restringiendo la variedad de materiales que se pueden analizar, su reducida área de barrido, así como la falta de automatización en algunas funciones, como, por ejemplo, el cambio del área de barrido (que se debe realizar manualmente). Este equipo es ideal para fines educativos y para aquéllos que están comenzando a familiarizarse con la técnica de STM.

En cuanto a equipos comerciales más complejos, un ejemplo es el JEOL JSPM-5200 (fig. 2 b). Este equipo es estacionario, demanda un espacio de trabajo bastante amplio, 
FIGURA 2. Ejemplos de equipos comerciales de STM. (a) Nanosurf easyScan E-STM (sencillo, portátil, fácil en su manejo, económico - un costo aproximado de US\$ 10,000); (b) JEOL JSPM-5200 (sofisticado, estacionario, requiere de conocimiento más profundo de la técnica, medianamente costoso - un costo aproximado de US\$200,000); y (c) Omicron VT UHV SPM (muy sofisticado, estacionario, requiere de conocimiento muy profundo de la técnica de STM, muy costoso - un costo aproximado de US\$ $\$ 00,000$ ). La imagen (c) es cortesía de la Dra. Michelle Simmons (Atomic Fabrication Facility, Centre of Excellence for Quantum Computer Technology, University of New South Wales, Sydney, Australia).

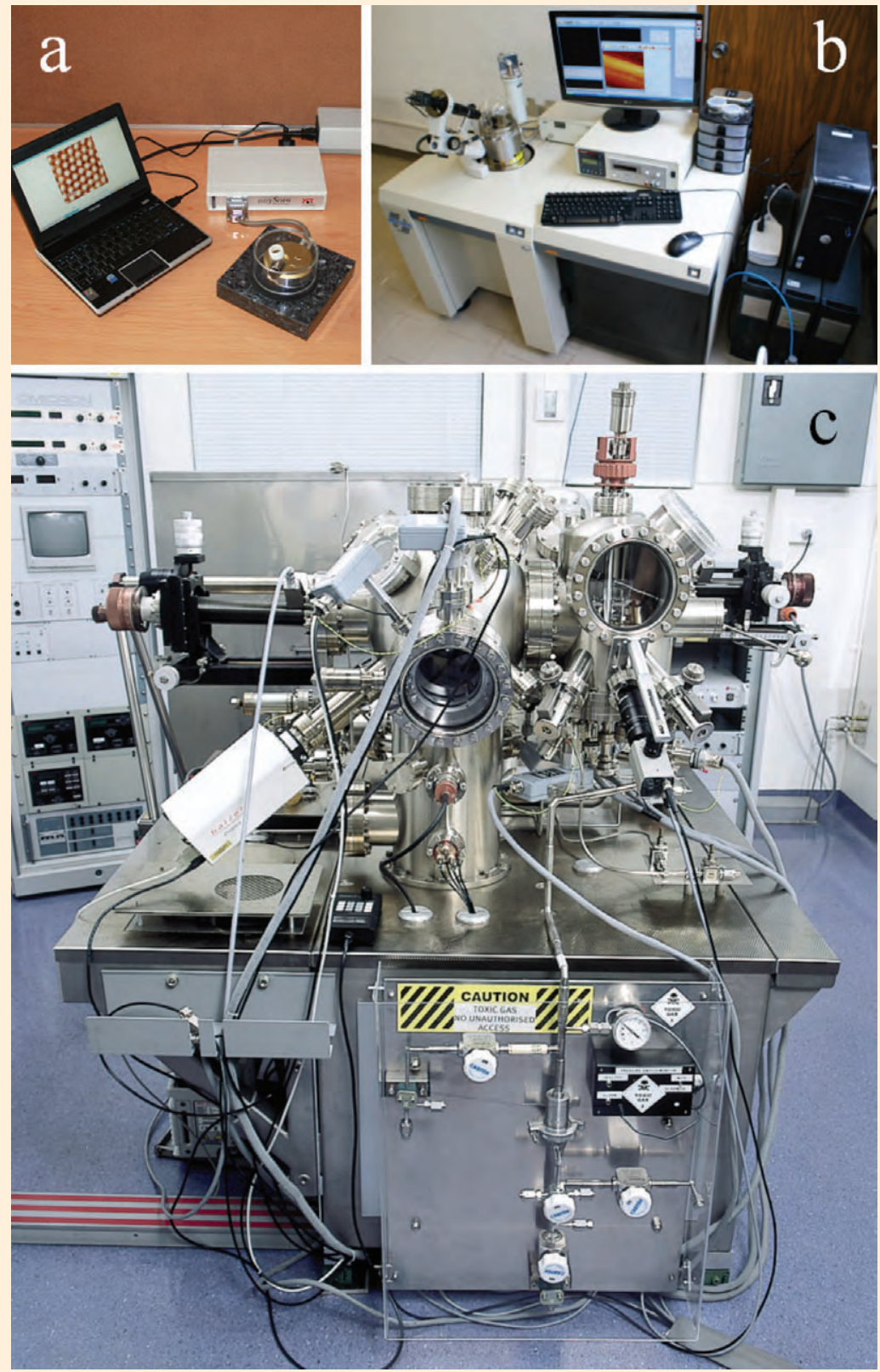


tiene un costo mediano, y su manejo requiere de condiciones de operación más específicas así como un conocimiento más profundo de la técnica de STM. JEOL JSPM5200, además de STM, también opera con otras variantes de microscopía de barrido como la de fuerza atómica (AFM) y espectroscopía de barrido de efecto túnel (STS), entre otras, por lo que algunos componentes como, por ejemplo, el amplificador de AFM y el láser son parte del equipo pero no se usan para STM. Los componentes principales del equipo incluyen una cabeza, una base, una mesa antivibratoria, una bomba de vacío, un controlador, una computadora con el software correspondiente, un compresor de aire para aislamiento antivibratorio, una cámara de video CCD, además de una serie de conectores y puertos. La cabeza contiene al portapuntas con la punta, conectores a la base, además de algunos componentes necesarios para el modo AFM. La base contiene al escáner en que se monta el portamuestras con el sustrato y material a analizar (por lo que, a diferencia del easyScan E-STM, en este caso se mueve la muestra con respecto a la punta, y no viceversa), tornillos para aproximación manual y cambios de posición, diversos conectores, puertos para gases, etc. La cabeza y parte de la base se cubren por una tapa de vidrio que sirve para proteger los componentes expuestos y posibilita la creación de un sistema cerrado y controlado para la operación en diversas condiciones de presión, gas y temperatura. El equipo trabaja en condiciones de presión desde 1 atm hasta alto vacío, mientras que la temperatura de operación abarca entre los 130 y 773 K [6]. El escáner es cilíndrico, y se puede encontrar en diversas longitudes, dependiendo del área de barrido que se quiere abarcar y resolución que se pretende alcanzar. Este equipo de STM brinda una gran precisión analítica por su estructura y aislamiento antivibratorio, y gracias a su versatilidad en las condiciones de operación permite analizar muestras de naturaleza muy variada. Por otro lado, el software permite modificar diversos parámetros del barrido, por lo que éstos se pueden adaptar conforme a las propiedades de la muestra, condiciones, y los objetivos del análisis. Una desventaja del JEOL JSPM-5200 es que, al operar en condiciones de alto vacío o baja temperatura, la tapa de vidrio que protege la cabeza no puede ser separada de la base, imposibilitando el intercambio de la muestra o la punta. Asimismo, la colocación manual de la muestra en el portamuestras puede ocasionar daño mecánico al escáner. Por otro lado, no hay forma de marcar la superficie de la muestra con el fin de volver a analizar determinado sitio de interés.

El equipo de STM más sofisticado fabricado hasta la fecha es posiblemente el Omicron VT UHV SPM (fabricado por Omicron NanoTechnology; VT, temperatura variable, y UHV, ultra-alto vacío, por sus siglas en inglés) (fig. 2c). Es un equipo de alto rendimiento, precisión y versatilidad. Al mismo tiempo, es costoso y requiere de condiciones de instalación muy estrictas así como un conocimiento sumamente profundo de la técnica de STM. Desde 1996 a la fecha, se han instalado más de 400 unidades en diversos laboratorios del mundo. El Omicron VT UHV SPM opera a temperaturas en un rango de 25 a $1500 \mathrm{~K}$, lo cual permite no solamente analizar materiales con distintas propiedades, sino también estudiar y controlar diversos procesos moleculares que ocurren sobre la superficie de la muestra. La presión con que se puede trabajar abarca de $1 \mathrm{~atm}$ hasta condiciones de UHV. Con este equipo es posible el crecimiento de algunos materiales simultáneamente con la obtención de imágenes del proceso, lo cual es extremadamente útil en la nanociencia y nanotecnología. El equipo también opera en modo de AFM y espectroscopía de STS, e igual que en el caso del JEOL JSPM5200 puede incluir una cámara CCD para el control de la posición de la punta con respecto a la muestra. El escáner en este caso también es cilíndrico. El equipo tiene un 
excelente aislamiento antivibratorio, lo que permite la obtención exitosa de imágenes con resolución atómica de diferentes materiales. En el Omicron VT UHV SPM existe la posibilidad de marcar la muestra para ubicar las nanoestructuras de interés en la superficie; esto último es una ventaja significativa con respecto a otros equipos de STM ya que resulta muy conveniente poder analizar un sitio repetidamente, especialmente al estudiar un proceso molecular. Otra ventaja importante es el manejo automatizado de las muestras ya que el equipo tiene un dispositivo de transferencia (manipulador) desde la cámara en que se prepara la muestra hacia la cámara de UHV, en principio inaccesible desde el exterior durante la operación. Asimismo, es posible el intercambio de punta automatizado para condiciones de UHV. Una ventaja adicional es que el manejo del escáner se hace de forma automatizada mediante control remoto, lo cual reduce el riesgo de daño mecánico [7]. El Omicron VT UHV SPM es más apropiado para expertos en STM, así como para fines muy específicos de nanociencia y nanotecnología. El Omicron LT UHV SPM (LT, temperaturas bajas, por sus siglas en inglés) es un equipo muy parecido al Omicron VT UHV SPM, pero en este caso la temperatura de operación puede ser aún menor que $5 \mathrm{~K}$. Esto, junto con su excelente aislamiento antivibratorio, es de gran utilidad para reducir la movilidad de los átomos y moléculas sobre el sustrato en que fueron depositadas, permitiendo obtener imágenes de excelente calidad, aún tratándose de átomos y moléculas individuales [8].

\section{HeRRAMIENTAS COMPUTACIONALES}

El STM comúnmente se utiliza en conjunto con algunas herramientas computacionales que, por ejemplo, pueden servir para el procesamiento de las imágenes obtenidas, o para simular teóricamente el sistema analizado. Tales herramientas son disponibles a través de diversos programas que se pueden descargar de Internet sin costo, o se pueden adquirir comercialmente en un amplio rango de precios.

Tras una sesión de STM, se obtienen imágenes "en crudo" que frecuentemente deben pasar por un proceso de manipulación para mejorar su calidad así como para analizarlas y obtener información más profunda de lo registrado en la imagen. Existen diversos programas computacionales que sirven para ambos propósitos. Con el fin de mejorar la calidad de las imágenes, los programas permiten mejorar el contraste, aumentar o disminuir el brillo, remover líneas de ruido, cambiar el modelo de iluminación, aplanar la imagen, etc. Para el análisis de las imágenes, tales programas permiten medir el tamaño de las estructuras de interés capturadas, construir perfiles topográficos, recortar la imagen para únicamente mostrar el área de interés, hacer un "zoom" hacia alguna estructura en particular, rotar la imagen, modificar la paleta de colores con fines ilustrativos, mostrar la imagen en 3D, etc. Este conjunto de posibilidades es de suma importancia para obtener la mayor cantidad de información admisible a partir de una imagen de STM. Frecuentemente, los equipos de STM comerciales incluyen algún programa propio para el procesamiento de las imágenes; asimismo, existen programas gratuitos como, por ejemplo, el WSxM [9] que se pueden descargar de Internet.

Por otro lado, para obtener un panorama más amplio de los fenómenos registrados en las imágenes de STM, es común recurrir a su comparación con simulaciones por modelado molecular. Para este fin, se han diseñado diversos programas computacionales de diferentes niveles de dificultad, costos computacionales y sistemas que son capaces de analizar. Dentro de cada programa, existen diversas opciones que per- 
miten configurarlo con base en las propiedades químicas y dimensiones de las moléculas de interés, así como el propósito del análisis. Algunos programas inclusive pueden simular las condiciones de la muestra, incluyendo la temperatura, solvente, sustrato, etc. El objetivo general de las simulaciones es construir un modelo lo más similar posible al experimental, para predecir el comportamiento más energéticamente favorable de las moléculas involucradas, abarcando su estructura tridimensional, posición con respecto a otros componentes del sistema, interacción con los mismos y con el medio, las posibles geometrías de ensamble entre varias moléculas, etc. La gran ventaja de esto es poder predecir o comprobar lo que está ocurriendo en la realidad, e interpretar con mayor fundamento teórico las imágenes de STM. Las simulaciones, además, pueden servir a modo de un diagrama explicativo de los fenómenos capturados en las imágenes, como se verá a continuación. Un ejemplo de programa comercial para modelado molecular es el HyperChem de Hypercube Inc. [10] (mediante el cual se construyeron algunos de los modelos mencionados abajo en este artículo).

\section{IMAGENES A NANOESCALA}

A la fecha, el STM ha permitido obtener imágenes a nanoescala de una diversidad extraordinaria de materiales, comenzando por los sustratos mismos, moléculas tanto individuales como arregladas en ensambles complejos, materiales híbridos, etc. El análisis de los sustratos empleados para depositar los materiales a estudiar es el caso más sencillo para la obtención de imágenes a nanoescala, pero también representa un área de gran interés en la nanociencia. Un ejemplo destacado es el grafito en su forma de HOPG que, como se había mencionado, es uno de los sustratos más ampliamente utilizados para los análisis por STM. Es un material de carbono de alta pureza, anisotrópico, hidrofóbico, no polar, buen conductor, inerte, estable, de superficie plana y fácil de limpiar. Tiene una estructura laminar compuesta de hojas de grafeno, apiladas a una distancia de aproximadamente $0.335 \mathrm{~nm}$ y unidas entre sí por fuerzas de van der Waals. En la hoja de grafeno los átomos de carbono tienen hibridación $\mathrm{sp}^{2}$ resultando en una red de hexágonos en que cada átomo se conecta con otros tres, a una distancia de aproximadamente $0.142 \mathrm{~nm}$ y con ángulos de $120^{\circ}$. La limpieza de la superficie del HOPG se realiza por remoción de las capas superficiales mediante un trozo de cinta adhesiva, produciendo un sustrato sin impurezas adsorbidas, adecuado para el depósito de los materiales de interés. La caracterización previa del sustrato es importante desde tres puntos de vista principales. Primero, el HOPG, a pesar de sus ventajas, frecuentemente presenta algunos defectos de superficie, como por ejemplo fibras, escalones, tiras, impurezas y trozos de grafito roto, que pueden complicar la interpretación de las imágenes de STM [11]. Segundo, debido a que los defectos alteran la estructura electrónica original del HOPG, pueden servir como sitios preferenciales de adsorción para algunas moléculas depositadas. Y tercero, al encontrar los parámetros de STM para lograr la resolución atómica del HOPG, resulta más fácil calibrar los parámetros del barrido para visualizar con resolución atómica las moléculas depositadas. Las imágenes con resolución atómica de la superficie del HOPG se pueden obtener utilizando los equipos más sencillos de STM. En tales imágenes se pueden observar patrones de distintas tonalidades que representan el relieve de la superficie del grafito (fig. 3a). Los puntos más claros que sobresalen en la superficie se denominan sitios $\beta$ y representan a átomos de carbono que carecen de un átomo de carbono vecino en la capa de grafeno inmediata inferior a la superficial. Los puntos más oscuros se ubi- 
FIGURA 3. Imágenes de STM a nanoescala de la superficie de HOPG. (a) Superficie del HOPG normal con resolución atómica. Se observa un patrón de distintas tonalidades, donde los puntos más claros sobresalen en la superficie, mientras que los puntos más oscuros se ubican más abajo; representando a átomos de carbono sin y con un átomo de carbono en la capa inmediata inferior, respectivamente. La distancia entre dos puntos claros o dos puntos oscuros contiguos es de aprox. $0.246 \mathrm{~nm}$. (b) Súperred formada en la superficie de HOPG. Se observa una red hexagonal súperperiódica, causada por la alteración en la correspondencia entre los átomos de carbono de la capa superficial y la inmediata inferior del HOPG. Estas imágenes fueron obtenidas mediante un equipo JEOL JSPM-5200; sin embargo, un Nanosurf easyScan E-STM es capaz de producir en HOPG una resolución similar.
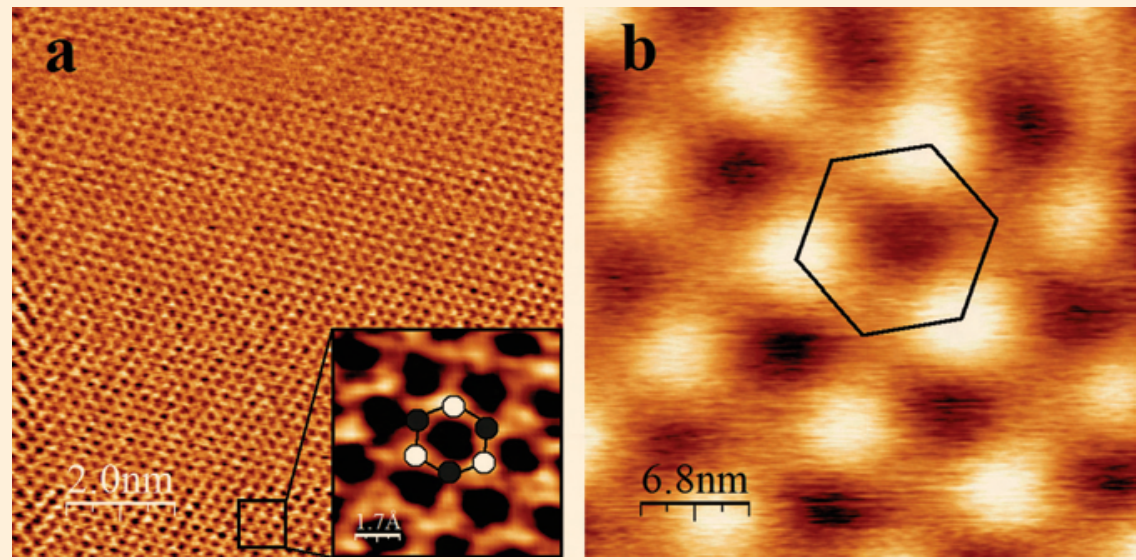

can más abajo y denominan sitios $\alpha$, representando a átomos de carbono que tienen a un átomo de carbono vecino en la capa inmediata inferior, lo cual causa una reducción en su densidad de estados electrónicos en el nivel de Fermi. De esta forma, la superficie del grafito se compone de dos subredes: $\alpha$ y $\beta$, donde la distancia entre dos sitios $\alpha$ o $\beta$ contiguos es de aproximadamente $0.246 \mathrm{~nm}$ [11]. Conocer esta periodicidad es de gran importancia para distinguir al sustrato de los materiales depositados y de defectos topológicos del HOPG conocidos como súperredes. El fenómeno de súperredes se produce principalmente por defectos intrínsecos del cristal de grafito durante su fabricación o por daños físicos durante su manejo, ocasionando la rotación de una o más hojas de grafeno superficiales con respecto a las capas inferiores [11]. Las súperredes también se pueden observar incluso con los equipos más sencillos de STM. En las imágenes topográficas de STM, las súperredes se observan como estructuras hexagonales superperiódicas (fig. 3b). Esto se debe a que, al ocurrir la rotación, se altera la correspondencia entre los átomos de carbono de la(s) capa(s) superficial(es) del HOPG con aquéllos de la capa inmediata inferior. Consecuentemente, los átomos de carbono de la capa superficial pueden ahora encontrarse por encima de cualquier sitio de la capa inmediata inferior, como puede ser un sitio $\alpha, \beta$ o algún punto entre ambos, resultando en el cambio de periodicidad observada en la imagen de STM. La periodicidad de la súperred depende del ángulo de rotación. La presencia de las súperredes puede complicar el análisis de las imágenes de STM debido a que se puede confundir, por ejemplo, con ensambles de moléculas depositadas, sobre todo si éstos se forman como estructuras periódicas [11]. Por otro lado, las súperredes presentan propiedades electrónicas peculiares, por lo que posiblemente podrían servir como 
una especie de moldes para la adsorción ordenada con periodicidad regular de algunos materiales [12]. De todo lo anterior se puede concluir que la caracterización detallada por STM del HOPG usado como sustrato es crítico para conocer la superficie en que se van a depositar los materiales a analizar, tomando en cuenta la posible presencia de defectos topológicos, entre ellos las súperredes. Cabe mencionar que la obtención de imágenes de la estructura atómica del grafito resalta la gran sensibilidad de la técnica de STM.

\section{Autoensambles moleculares}

Recientemente, el STM se ha podido utilizar exitosamente para analizar los autoensambles moleculares (MSA por sus siglas en inglés), que juegan un papel crucial en la nanociencia y la aproximación bottom-up de la nanotecnología. El fenómeno de MSA consiste en la formación espontánea de estructuras supramoleculares complejas, definidas por la forma y propiedades de las moléculas involucradas, y donde los factores externos no dirigen el proceso del ensamble [13]. El autoensamble es una estrategia frecuentemente observada en los sistemas biológicos, un ejemplo ilustrativo siendo el virus del mosaico del tabaco (TMV por sus siglas en inglés) en el que 2130 subunidades idénticas de la proteína de cubierta se autoensamblan de forma helicoidal para producir la cápside viral. La nanotecnología tiene gran interés en imitar los autoensambles que ocurren naturalmente en sistemas biológicos, a raíz de la gran especificidad y eficiencia del proceso. Un tipo de MSAs son las monocapas autoensambladas (SAMs por sus siglas en inglés). Las SAMs se forman por la adsorción y asociación espontánea de moléculas en una sola capa sobre la superficie de un sustrato cuya interacción con las moléculas depositadas es energéticamente favorable. Las SAMs permiten transferir las propiedades de las moléculas depositadas a una superficie homogénea [14], y pueden ser muy versátiles ya que tanto las moléculas de interés como el sustrato pueden ser de forma, tamaño y propiedades variadas. Un ejemplo de moléculas ampliamente utilizadas para producir y estudiar a las SAMs son las porfirinas. Estas moléculas presentan diversas ventajas incluyendo su alta estabilidad, geometría planar, intensa adsorción y emisión electrónicas, y la facilidad de modificar sus propiedades ópticas y redox por una metalación apropiada ([15] y literatura de ahí). Las porfirinas son capaces de formar autoensambles de distintas arquitecturas. En estos autoensambles, las moléculas se mantienen unidas por interacciones no covalentes como las hidrofóbicas, van der Waals, puentes de hidrógeno, apilamiento $\pi-\pi$, etc., resultando en sistemas termodinámicamente estables y capaces de autorreparación [16]. Las SAMs de porfirinas tienen aplicaciones en la fabricación de sensores y catalizadores, sustratos para reacciones químicas, sistemas colectores de energía, entre muchas otras. Por medio de la técnica de STM se han podido estudiar SAMs de diversas porfirinas en distintos sustratos, el HOPG y el Au(III) siendo los más utilizados. El HOPG es un sustrato muy cómodo para la obtención de SAMs de porfirinas dado que las interacciones no covalentes entre ambos permiten la movilidad necesaria para que las porfirinas encuentren el acomodo más energéticamente favorable. Las imágenes a nanoescala de autoensambles de porfirinas representan un ejemplo más complejo de la aplicación de la técnica de STM que el estudio de los sustratos, y son difíciles de obtener con los equipos más sencillos debido a factores como la movilidad de las moléculas analizadas sobre el sustrato. Por esta 
razón, para obtener imágenes de calidad óptima de estos sistemas, se requiere de un excelente aislamiento antivibratorio, la posibilidad de modificar numerosos parámetros de barrido, así como en ocasiones la capacidad de operar en ambientes de UHV y temperatura baja. El análisis de tales imágenes de STM, apoyado además en simulaciones por modelado molecular, ha permitido obtener información valiosa acerca del proceso del autoensamble de porfirinas sobre HOPG, desde los arreglos más sencillos hasta los más complejos como las SAMs. Un ejemplo interesante son los autoensambles de meso-tetrafenilporfinas (TPPs por sus siglas en inglés). Estas porfirinas son sintéticas, y se pueden emplear en su forma de ligando libre $\left(\mathrm{H}_{2} \mathrm{TPP}\right)$ o con metales de transición en el centro de la molécula, que pueden ser de cobalto (Co(II)), níquel (Ni), magnesio (Mg), etc. El ligando libre consiste en una porfina con cuatro grupos fenilo como sustituyentes en posición meso, resultando en una molécula planar (en su mayor parte), simétrica y rica en electrones $\pi$. La meso-tetrafenilporfina de níquel o NiTPP representa un caso muy atractivo para su estudio por STM gracias a la presencia del átomo central de Ni. Al analizar por STM muestras de NiTPP depositadas sobre la superficie de HOPG, se obtienen imágenes en que cada molécula se distingue como una mancha brillante puesto que la corriente de túnel pasa intensamente a través del átomo del metal de transición. Un ejemplo de una molécula individual de NiTPP se muestra en la figura 4a. Esta molécula se encuentra aislada sobre la superficie del HOPG, y exhibe una notable apariencia helicoidal, similar a la que se puede observar en un modelo molecular construido mediante el programa HyperChem 7.5 [10] para simular la adsorción de una molécula de NiTPP sobre la capa superficial del HOPG (fig. 4b). Las imágenes de STM sugieren que el autoensamble de NiTPP ocurre en monocapa, en que las moléculas individuales adsorbidas sobre el sustrato interactúan entre sí a través del apilamiento $\pi$ entre los anillos $\mathrm{C}_{6} \mathrm{H}_{5}$ para formar largas hileras aisladas (fig. 4c). En la figura $4 \mathrm{~d}$ se presenta un modelo molecular que ilustra lo que ocurre en la figura 4c. Las imágenes revelan que tales hileras aisladas de NiTPP posteriormente se ensamblan entre sí para formar arreglos más complejos, que frecuentemente ocurren en forma de cintas anchas (cuyo tamaño depende del número de hileras involucradas) y varios micrómetros de longitud sobre la superficie del HOPG (fig. 4e). Estos arreglos indican ser altamente estables, lo cual es evidente por su gran longitud y por el hecho de que permanecen ininterrumpidas al cruzar por encima de diversos defectos topológicos del HOPG. Tales cintas también se han observado repetidamente en los casos de $\mathrm{H}_{2}$ TPP y CoTPP, sugiriendo que este fenómeno es un caso común para las meso-tetrafenilporfinas. Además, similares cintas autoensambladas de distintos tipos de porfirinas se han reportado en múltiples estudios, indicando que efectivamente hay una tendencia de las porfirinas por formar tales arquitecturas. Los autoensambles de TPPs también pueden encontrarse en forma de tapetes que cubren grandes superficies del sustrato, es decir, en forma de SAMs. Un ejemplo de esto se muestra en la figura $4 \mathrm{f}$, en que se puede observar la superficie de HOPG completamente cubierta por moléculas de CoTPP formando una SAM. Sin embargo, para que ocurra la formación de tal arreglo, deben confluir diversas condiciones que lo favorezcan, como, por ejemplo, una concentración de CoTPP adecuada, una distribución relativamente homogénea sobre el sustrato, una evaporación del solvente relativamente lenta como para proveer un medio en que las moléculas se puedan desplazar con mayor facilidad, así como una temperatura adecuada para otorgar la energía necesaria para que múltiples moléculas de porfirinas se encuentren en el espacio y formen tapetes extensos. Las imágenes de la figura 4 fueron 
FIGURA 4. Autoensambles de TPP sobre la superficie de HOPG. Imagen de STM (a) y modelo correspondiente de una molécula individual de NiTPP aislada sobre el sustrato (b). Imagen de STM (c) y modelo correspondiente (d) de hileras individuales de NiTPP. (e) Imagen de STM de un cinta autoensamblada de NiTPP, formada por varias hileras individuales paralelas e interactuando entre sí. (f) Imagen de STM de una monocapa autoensamblada (SAM) de moléculas de CoTPP, que se visualiza como un tapete extenso que cubre por completo la superficie del HOPG. Imágenes obtenidas mediante el equipo JEOL JSPM5200 (en colaboración con el Dr. Edgar Álvarez Zauco).
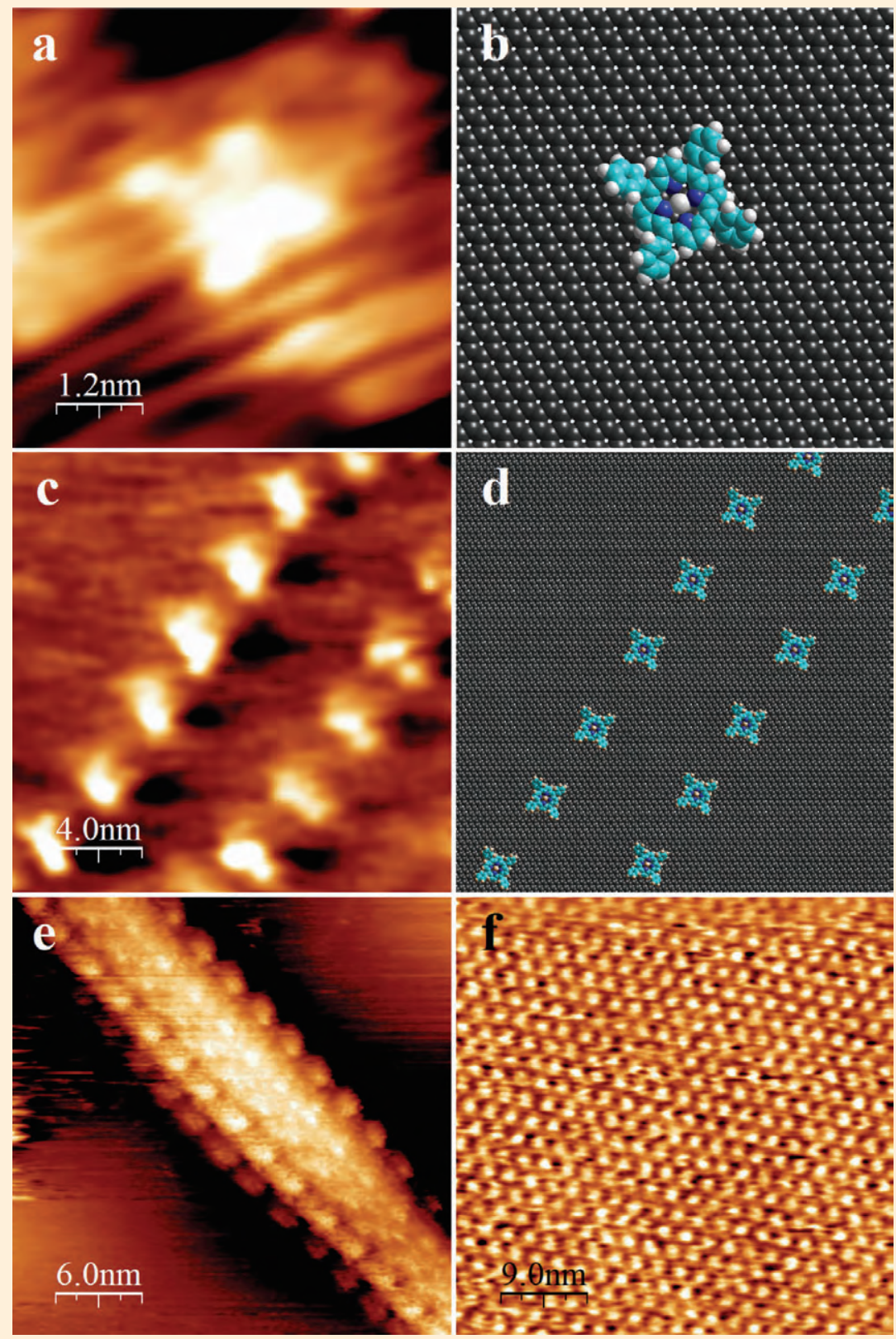
obtenidas en condiciones de temperatura y presión ambientales, empleando JEOL JSPM-5200, descrito previamente, e ilustran la capacidad de este equipo para analizar fenómenos como los autoensambles moleculares. Cabe mencionar que este tipo de equipos de STM presentan limitaciones para visualizar la estructura atómica de moléculas como las porfirinas por la dificultad de operación en condiciones de alto vacío y a bajas temperaturas. Esto se debe a que la punta frecuentemente se ensucia con partículas presentes en la muestra (impurezas o las porfirinas mismas), mientras que por la configuración del equipo, durante la operación en estas condiciones la punta y la muestra se encuentran inaccesibles, imposibilitando el intercambio de la punta sucia por una nueva.

\section{GeOMETRÍA de LAS MOLÉCULAS}

Mientras que la observación de autoensambles moleculares es accesible para equipos de STM de mediana complejidad, sólo equipos tan sofisticados como el Omicron VT UHV SPM u Omicron LT UHV SPM pueden permitir el análisis con precisión atómica del comportamiento de los sistemas de interés en un amplio rango de temperaturas. Un ejemplo ilustrativo es el estudio realizado por Baber y colaboradores [17], en el que se empleó el Omicron LT UHV SPM para investigar la estructura en escala atómica de aleaciones bimetálicas de $\mathrm{Pd} / \mathrm{Au}(111)$ (paladio con oro). Estas aleaciones son útiles como catalizadores de múltiples reacciones químicas importantes, mientras que su arreglo en escala atómica (dado por las interacciones electrónicas resultantes entre ambos metales) puede afectar significativamente su reactividad y selectividad. El estudio consistió en la deposición directa de átomos de Pd (provenientes de un alambre de este material) sobre un cristal de Au(111) dentro de la cámara de preparación de muestras del Omicron LT UHV SPM a distintas temperaturas. Las muestras posteriormente se analizaron por STM durante varias horas a una temperatura constante de $7 \mathrm{~K}$ de la punta y de la muestra. Los resultados obtenidos se presentan en la figura 5 (mediante un esquema y la imagen de STM correspondiente), donde se ilustra la dependencia entre la temperatura durante el proceso de la aleación y la incorporación de los átomos de Pd sobre el Au(111). Según estos resultados, a una temperatura alta de $460 \mathrm{~K}$, la mayoría de los átomos de Pd se encuentran en la capa subsuperficial (por debajo de la superficie) del $\mathrm{Au}(111)$ y se visualizan como depresiones trilobuladas en la imagen de STM (fig. 5a). A una temperatura de $380 \mathrm{~K}$, los átomos de Pd se incorporan principalmente sobre la capa superficial pero también por debajo de ella, observándose en la imagen de STM como protrusiones y depresiones trilobuladas, respectivamente (fig. 5b). Por último, tras una deposición a 290 K, se encontró que los átomos de $\mathrm{Pd}$ intercambian de lugar con los átomos de $\mathrm{Au}$ en sitios de dislocaciones de borde y, posteriormente, sirven como centros de nucleación para el crecimiento de monocapas en forma de islas de Pd (fig. 5c). Este estudio ejemplifica la aplicación del equipo de STM modelo Omicron LT UHV SPM para la fabricación de materiales como las aleaciones bimetálicas de $\mathrm{Pd} / \mathrm{Au}$ de distintas geometrías empleando distintas temperaturas durante la deposición, y la observación de las arquitecturas obtenidas en escala atómica a una temperatura baja y constante. Este tipo de estudios son de crucial importancia para la nanofabricación dado que permiten controlar con gran precisión las condiciones para la construcción de diversos materiales, y el análisis detallado de los resultados obtenidos. 
FIGURA 5. Dependencia entre la temperatura durante el proceso de la aleación y la incorporación de los átomos de Pd sobre el Au(111) (esquema de vista lateral y la imagen de STM correspondiente). (a) Después de la deposición de Pd a $460 \mathrm{~K}$, los átomos de Pd residen en la capa subsuperficial y aparecen en la imagen de STM como depresiones trilobuladas (indicadas con triángulos rojos). (b) A una temperatura más baja $(380 \mathrm{~K})$, los átomos de Pd se incorporan en las capas superficiales y subsuperficiales: los átomos superficiales se visualizan como protrusiones, mientras que los subsuperficiales aparecen como depresiones trilobuladas. (c) Tras una deposición a $290 \mathrm{~K}$, los átomos de Pd intercambian de lugar con los átomos de Au en sitios de dislocaciones de borde, y posteriormente sirven como centros de nucleación para el crecimiento de monocapas en forma de islas pronunciadas de Pd en la superficie de $\mathrm{Au}$, constituidas por una mezcla de Pd y Au rica en Pd. Imágenes de STM obtenidas mediante el equipo Omicron LT UHV SPM. Reproducido con permiso de A. E. Baber et al. [17], ACS Nano, 2010, 4, 1637. (c) 2010 American Chemical Society.

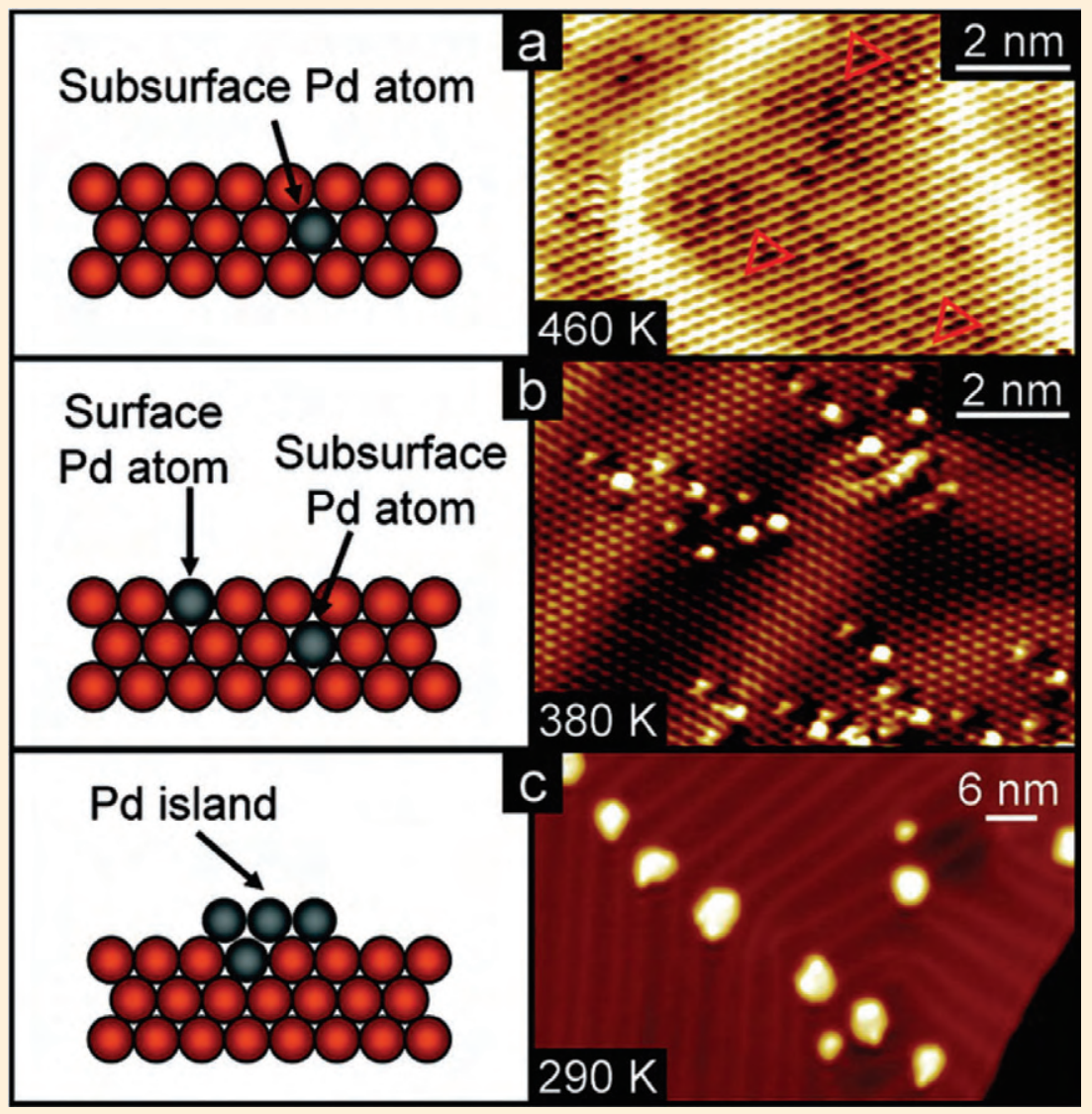

\section{ROTORES MOLECULARES}

Otro caso llamativo de la aplicación de la técnica de STM es la observación del movimiento de las moléculas en tiempo real. Esta aplicación juega un papel central para la fabricación de nanomáquinas denominadas rotores moleculares, activadas térmica o mecánicamente. Para volver realidad las diversas aplicaciones nanotecnológicas potenciales de estos dispositivos, es necesario dilucidar los mecanismos que rigen el 
fenómeno. Por ejemplo, en el estudio realizado por Tierney y colaboradores [18], se utilizó el equipo de STM Omicron LT UHV SPM para investigar la dinámica de la rotación de tioéteres (moléculas orgánicas con grupo funcional R-S-R) depositadas sobre sustratos de $\mathrm{Au}(111)$. Los tioéteres empleados incluyeron dimetil $\left(\mathrm{C}_{1}\right)$, dietil $\left(\mathrm{C}_{2}\right)$, dibutil $\left(\mathrm{C}_{4}\right)$ y dihexil $\left(\mathrm{C}_{6}\right)$ sulfuros. El análisis se realizó en condiciones de UHV, y a temperaturas variadas con el fin de observar su efecto sobre la dinámica rotacional de los distintos tioéteres sobre la superficie del Au(111). Las imágenes de STM obtenidas en este estudio se presentan en la figura 6. Es evidente que a una temperatura de $7 \mathrm{~K}$ las moléculas de tioéter permanecen inmóviles y tienen una apariencia lineal, a excepción del dimetil sulfuro $\left(C_{1}\right)$ que se visualiza con forma hexagonal puesto que, por su baja barrera a la rotación, gira incluso a una temperatura tan baja como $7 \mathrm{~K}$. Al calentar la muestra a $16 \pm 2 \mathrm{~K}$, las moléculas de $\mathrm{C}_{2}, \mathrm{C}_{4} \mathrm{y} \mathrm{C}_{6}$ que permanecían inmóviles, comienzan a rotar, adquiriendo una apariencia hexagonal. Cabe mencionar que en este estudio se recurrió a simulaciones por modelado molecular para comprender mejor la dinámica de la rotación. Los resultados de estas simulaciones correspondieron bien con los resultados experimentales, comprobando la estrecha dependencia entre la temperatura y la rotación de los tioéteres. El estudio de los rotores moleculares implica el análisis del movimiento de moléculas individuales sobre sustratos sólidos, por lo que representa un caso más complejo de la aplicación del STM en la nanociencia y nanotecnología, que los anteriormente mencionados. Tales estudios únicamente se pueden realizar en equipos cuya sofisticación les permite operar en vacío y a una temperatura controlada por la duración del experimento entero, desde la preparación de la muestra hasta su análisis por STM.

\section{ReACCIONES Químicas}

Una verdadera aspiración de la nanociencia y la nanotecnología es la posibilidad de observar directamente los eventos de una reacción química paso por paso en escala atómica. Tal posibilidad podría no sólo revelar detalles novedosos, sino también permitir un control más preciso de la reacción con el fin de lograr algún objetivo particular. En este sentido, el STM una vez más resulta una herramienta muy potente: a la fecha ya existen algunos estudios en que se han logrado visualizar reacciones químicas en tiempo real, permitiendo grabar "películas" del proceso completo. Un ejemplo interesante es el reportado por Matthiesen y colaboradores [19], en el que se empleó la técnica de STM para observar el proceso de formación de agua sobre la superficie de dióxido de titanio $\left(\mathrm{TiO}_{2}(110)\right.$ ) en su forma rutilo (con estructura cristalina tetragonal). Como se puede ver en el modelo de bola y palo de la figura $7 \mathrm{a}$, una celda unitaria de la superficie del $\mathrm{TiO}_{2}(110)$ rutilo está formada por filas de átomos de titanio cinco (5f-Ti) y seis veces coordinados (6f-Ti), intercaladas en el mismo plano con filas de oxígeno tres veces coordinado. Por encima de este plano hay filas de oxígeno dos veces coordinado u oxígeno puente $\left(\mathrm{O}_{\mathrm{br}}\right)$. La superficie del $\mathrm{TiO}_{2}(110)$ presenta algunos defectos puntuales que incluyen vacantes de oxígeno puente $\left(\mathrm{O}_{\mathrm{br}} \mathrm{vac}\right)$, átomos de hidrógeno adsorbidos o adátomos de $\mathrm{H}, \mathrm{y}$ átomos individuales de oxígeno $\left(\mathrm{O}_{\mathrm{ot}}\right)$. En este estudio [19], se aprovechó la presencia de tales defectos para catalizar una reacción de oxidación mediante moléculas de $\mathrm{O}_{2}$ de adátomos de $\mathrm{H}$ sobre la superficie de $\mathrm{TiO}_{2}(110)$ rutilo. Brevemente, el experimento consistió en bombardear el $\mathrm{TiO}_{2}(110)$ con argón (Ar) seguido de su recocido térmico para producir una gran cantidad de $\mathrm{O}_{\mathrm{br}}$ vac, y su posterior exposición a agua 
Mundo Nano | Artículos | Vol. 3, No. 2, julio-diciembre, 2010 | www.mundonano.unam.mx

FIGURA 6. Imágenes de STM que revelan que los rotores moleculares de dialquil sulfuros unidos en la superficie del $\mathrm{Au}(111)$ comienzan a rotar al aumentar la temperatura. Las moléculas de dimetil $\left(\mathrm{C}_{1}\right)$, dietil $\left(C_{2}\right)$, dibutil $\left(C_{4}\right)$ y dihexil $\left(C_{6}\right)$ sulfuros se muestran como lineales vs hexagonales a bajas y altas temperaturas, respectivamente, a excepción de $C_{1}$. $C_{1}$ tiene una baja barrera a la rotación y parece estar rotando incluso a una temperatura de $7 \mathrm{~K}$. La barra de escala equivale a $1 \mathrm{~nm}$. Imágenes obtenidas mediante el equipo Omicron LT UHV SPM. Reproducido con permiso de H. L. Tierney et al. [18], J. Phys. Chem. C, 2009, 113, 10913. (C) 2009 American Chemical Society.

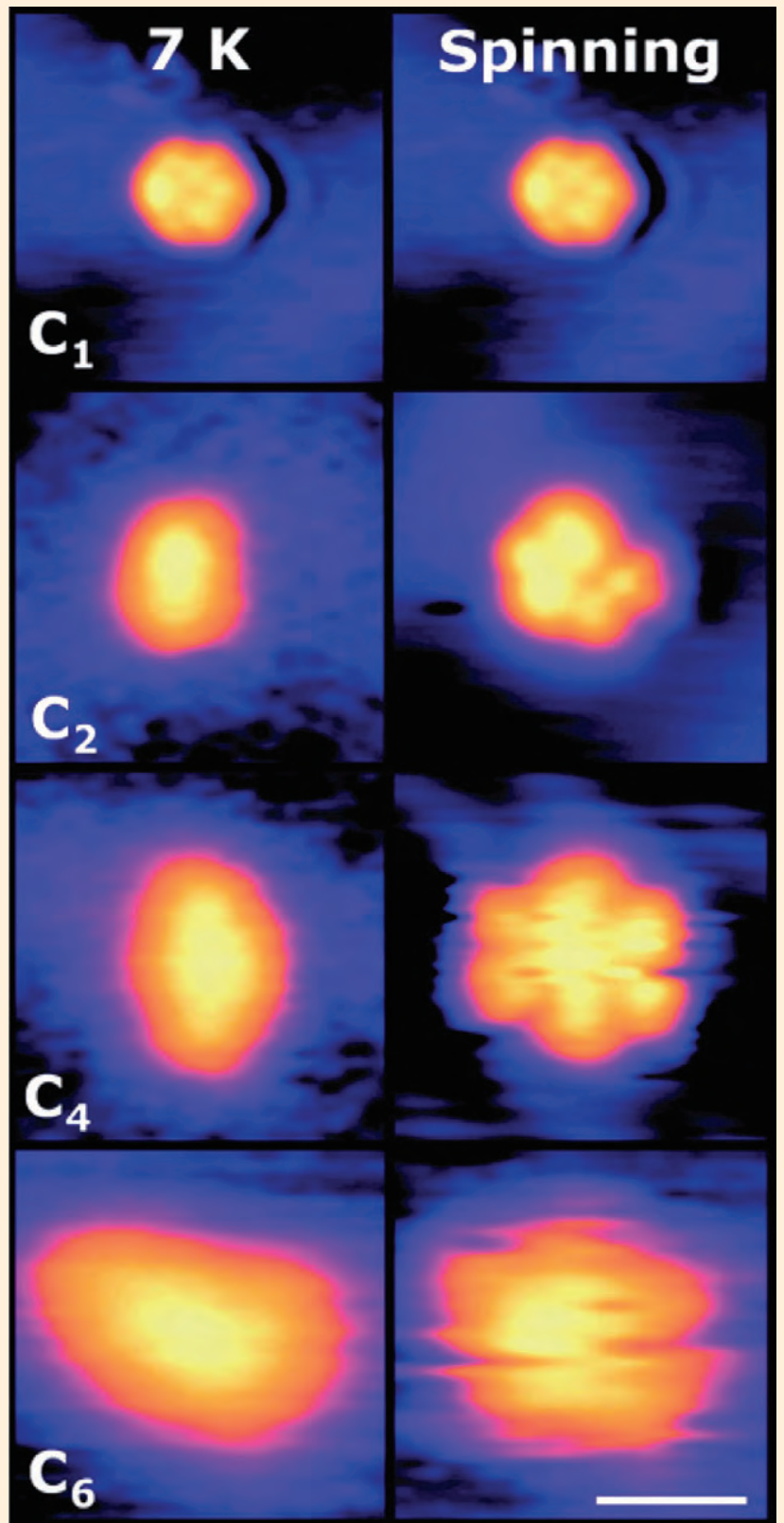


para obtener una superficie rica en adátomos de $\mathrm{H}\left(h-\mathrm{TiO}_{2}(110)\right)$. La formación de $h-\mathrm{TiO}_{2}(110)$ ocurre cuando el oxígeno del $\mathrm{H}_{2} \mathrm{O}$ llega a ocupar un sitio de $\mathrm{O}_{\mathrm{br}} \mathrm{vac}, \mathrm{y}$ por transferencia de protones al átomo de oxígeno vecino la molécula de agua se disocia para formar dos grupos $\mathrm{HO}_{\mathrm{br}} \mathrm{o}$ adátomos de $\mathrm{H}$. El $h-\mathrm{TiO}_{2}(110)$ resultante se puede ver en la imagen de STM (fig. 7b) donde se indican los adátomos de $\mathrm{H}$ formados, incluyendo los individuales, pareados, cercanos, y formando una hilera. Posteriormente, el $h-\mathrm{TiO}_{2}(110)$ se expuso a $4 \mathrm{~L} \mathrm{de} \mathrm{O}_{2}$ a $\sim 165 \mathrm{~K}$, causando la formación del primer intermediario $\mathrm{OH}_{-} \mathrm{O}$, que, por transferencia de $\mathrm{H}$ adicionales presentes en el sistema, pasó a formar intermediarios como $\mathrm{OH}_{-} \mathrm{OH}$ y $\mathrm{OH}_{-} \mathrm{OH}_{2}$ hasta llegar al producto final de dos moléculas de $\mathrm{H}_{2} \mathrm{O}$. En la imagen de STM de la figura 7c se indican algunos intermediarios así como las moléculas de $\mathrm{H}_{2} \mathrm{O}$ recién formadas, mientras que la figura $7 d$ es un acercamiento del área encuadrada en la figura 7c. Las imágenes de STM se obtuvieron a $110 \mathrm{~K}$. Este estudio se realizó empleando una cámara de UHV equipada con un STM casero de temperatura variable; esto ejemplifica la posibilidad de utilizar un equipo de STM comercial, y complementarlo con elementos adicionales conforme a las necesidades. Cabe mencionar que también en este caso se recurrió a la comparación de los resultados experimentales con simulaciones por modelado molecular, lo cual contribuyó tanto para corroborar la información obtenida, como para aclarar los pasos involucrados en el proceso desde la reducción del $\mathrm{TiO}_{2}(110)$ hasta la formación del $\mathrm{H}_{2} \mathrm{O}$ en su superficie.

\section{NANOMANIPULACIÓN}

Como se mencionó anteriormente, la interacción entre la punta del STM y la muestra analizada se puede aprovechar para manipular los átomos o moléculas depositadas sobre un sustrato. Esta aplicación de la técnica de STM es de gran interés para la aproximación bottom-up de la nanotecnología ya que puede permitir la construcción átomo por átomo de nanoestructuras novedosas con múltiples aplicaciones. Por ejemplo, Crommie y colaboradores [20] emplearon un equipo de STM criogénico para observar patrones de interferencia mecánica cuántica, generados por la dispersión de electrones bidimensionales (2D) a partir de átomos de hierro (Fe) artificialmente acomodados sobre la superficie de cobre cristalino $(\mathrm{Cu}(111))$. El experimento se realizó en condiciones de UHV a una temperatura de $4 \mathrm{~K}$. Los autores se basaron en el hecho de que los estados de superficie de las caras densamente empacadas de los metales nobles como el $\mathrm{Cu}$ se encuentran ocupados por un gas de electrones 2D casi libres, que puede ser visualizado por el STM. Al introducir una "impureza", como puede ser un átomo de $\mathrm{Fe}$, el estado de superficie del $\mathrm{Cu}(111)$ se perturba, ocasionando la dispersión de los electrones 2D y produciendo patrones de interferencia (lo cual ilustra el comportamiento de los electrones como ondas). En el experimento, se utilizó la punta del STM para deslizar cuidadosamente varios átomos individuales de Fe adsorbidos sobre la superficie del $\mathrm{Cu}(111)$ y acomodarlos en forma de anillos densamente empacados (con cortas distancias interatómicas), denominados corrales cuánticos. El proceso de la construcción de un corral cuántico de 177.4 Å se muestra en la figura 8, donde es evidente la evolución de los cambios en los patrones de interferencia conforme el anillo se va cerrando. Cuando el anillo se cierra por completo, se produce una barrera de dispersión continua donde los electrones se desplazan de un átomo de Fe a otro resultando en la formación de patrones de interferencia más complejos. Este ejemplo ilustra no sólo la posibilidad de manipular átomos individuales por me- 
Mundo Nano | Artículos | Vol. 3, No. 2, julio-diciembre, 2010 | www.mundonano.unam.mx

FIGURA 7. (a) Modelo de bola y palo de la superficie de $\mathrm{TiO}_{2}(110)(1 \times 1)$ con algunos de sus defectos puntuales. Las bolas grises grandes representan átomos de $\mathrm{O}$, las bolas rojas medianas a átomos superficiales de Ti seis veces coordinadas (6f-Ti) y cinco veces coordinados (5f-Ti). Las bolas grises pequeñas representan adátomos de $\mathrm{H}$. También se indican las especies de oxígeno puente $\left(\mathrm{O}_{\mathrm{br}}\right)$, vacantes de oxígeno $\left(\mathrm{O}_{\mathrm{br}} \mathrm{vac}\right)$ y especies enlazadas por encima $\left(\mathrm{O}_{\mathrm{ot}}\right)$. (b-d) Imágenes de STM de la superficie de $h$-TiO ${ }_{2}(110)$ antes (b) y después (c) de la exposición a $4 \mathrm{~L}$ de $\mathrm{O}_{2}$ a $\sim 165 \mathrm{~K}$. Los símbolos en (b) indican adátomos individuales de $\mathrm{H}$ (hexágono), adátomos pareados de $\mathrm{H}$ (cuadrado), adátomos de $\mathrm{H}$ cercanos (rectángulo de línea completa) y una hilera de adátomos de $\mathrm{H}$ cercanos (rectángulo de línea partida). Los círculos en (c) indican las especies nuevas en las depresiones del Ti, mientras que las flechas indican protrusiones pronunciadas dentro de las depresiones del Ti, con alturas típicamente observadas en el STM para moléculas de agua. El área cuadrada indicada en (c) (línea blanca partida) se muestra ampliada en (d). Un entramado cuadriculado se centró por encima de sitios $5 \mathrm{f}-\mathrm{Ti}$ en (d) tomando como referencia los adátomos de $\mathrm{H}$ (puntos blancos pequeños) para alinear en la dirección [001]. Las imágenes de STM se obtuvieron a $110 \mathrm{~K}$, empleando una cámara de UHV equipada con un STM casero de temperatura variable. Reproducido con permiso de J. Matthiesen et al. [19], ACS Nano, 2009, 3, 517. (c) 2009 American Chemical Society.
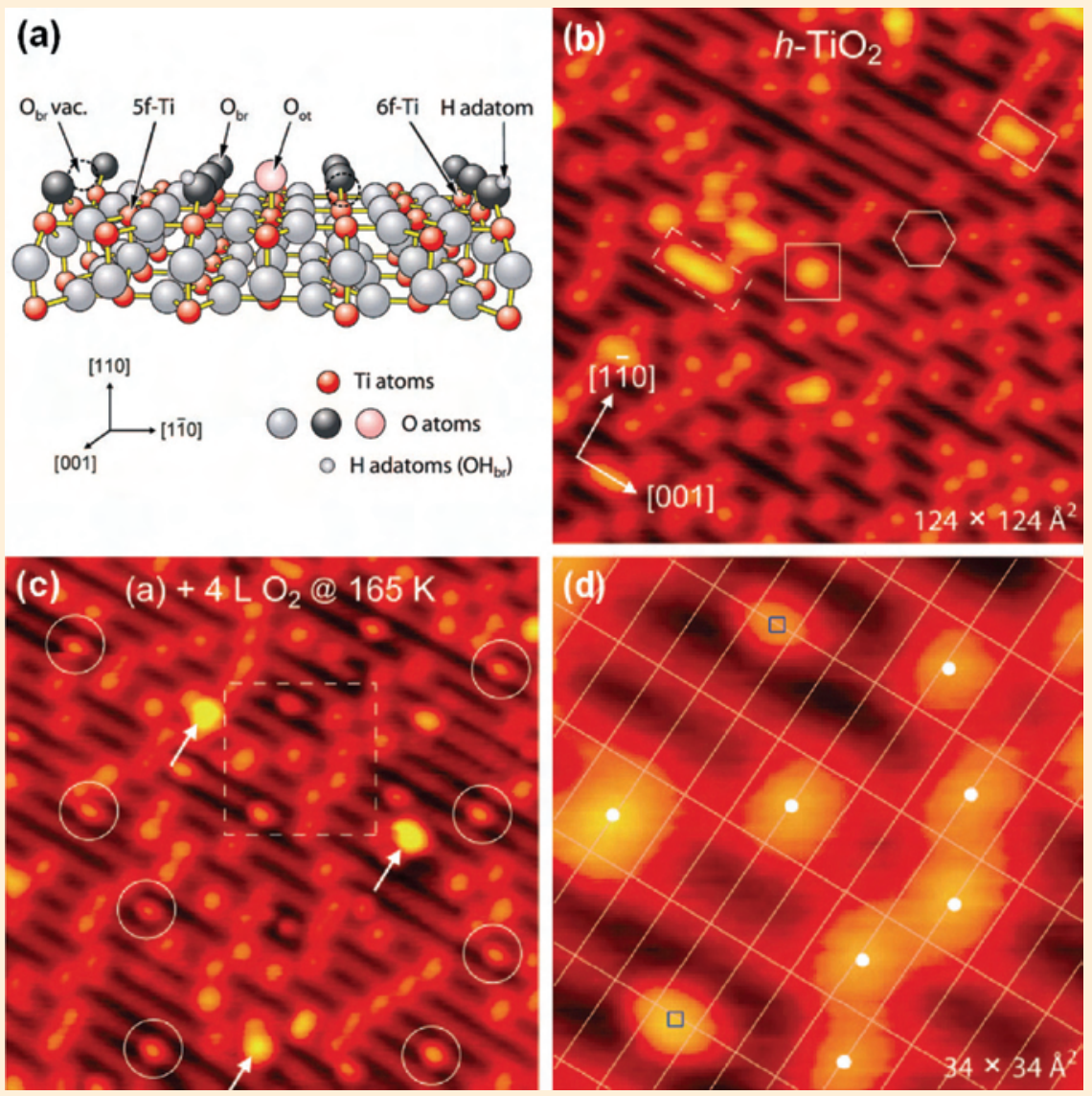
FIGURA 8. Imágenes de STM que ilustran el proceso de la construcción de un anillo de átomos individuales de Fe con diámetro de 177.4 Å. Es evidente la evolución en los patrones de interferencia conforme se va cerrando el anillo. Reproducido con permiso de M.F. Crommie et al. [20], Surface Science, 1996, 864, 361. (c) 1996 Elsevier.
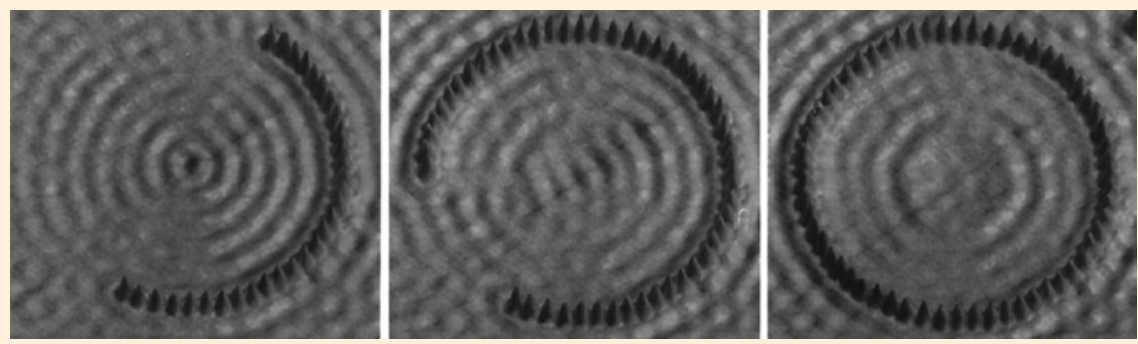

dio del STM, sino también la capacidad de la técnica para observar fenómenos tan finos como los patrones de interferencia mecánica cuántica.

\section{Conclusiones}

Con todo esto se puede ver que la técnica de STM por un lado permite la visualización y caracterización en escala nano de distintos materiales, ya sea átomos, moléculas, arreglos supramoleculares como las SAMs, materiales híbridos, rotores moleculares, e incluso reacciones químicas, por lo que se le puede considerar como los "ojos" que nos hacen posible asomarnos al mundo nano. Por otro lado, el STM también puede permitir la manipulación de moléculas o átomos individuales sobre sustratos sólidos, por lo que también se le puede considerar como una especie de "dedos" para la construcción de materiales nuevos o rearreglo de materiales existentes. Sin embargo, a la fecha, la función del STM como "ojos" se encuentra en una faceta mucho más avanzada que su función como "dedos". Esto se puede atribuir a múltiples razones. Por un lado, aún existen múltiples retos en la instrumentación de los equipos de STM como, por ejemplo, la automatización de sus funciones y el control preciso de todas las variables existentes. Adicionalmente, a la fecha son relativamente pocos los laboratorios en el mundo que tienen acceso a los equipos de STM suficientemente sofisticados que pueden permitir la manipulación en nanoescala de los materiales de interés. Por otro lado, debido a la juventud de la técnica en sí, y más aún del campo de la nanomanipulación por medio del STM, hace falta personal suficientemente capacitado para manejar una técnica tan compleja y multidisciplinaria. Por último, se debe tomar en consideración la gran complejidad e impredictibilidad de los sistemas analizados, por más sencillos que aparenten ser. Esto no representa una situación desalentadora, al contrario, revela un universo con infinitas posibilidades a explorar, y una multitud de caminos en cuyo recorrido se pueden descubrir fenómenos inesperados y sorprendentes, y nuevas aplicaciones en múltiples áreas de la ciencia. Y, seguramente, con el paso del tiempo, y acumulando los esfuerzos de todos aquéllos involucrados en los campos de la nanociencia y la nanotecnología, la nanomanipulación podrá llegar a una faceta tan avanzada como la de la caracterización de superficies por medio del STM. 


\section{REFERENCIAS}

[1] G. Binnig and H. Rohrer. 1986. "Scanning tunneling microscopy". IBM Journal of Research and Development, 30, 355.

[2] L. J. Whitman. 1998. "Tunneling microscopy and spectroscopy”. Encyclopedia of Applied Physics, 22, 361.

[3] R. Wiesendanger and H. J. Güntherodt (eds.) 1997, Scanning tunneling microscopy III. Theory of STM and related scanning probe methods. Berlín: Springer-Verlag, $2^{\text {nd }}$ ed., $402 \mathrm{pp}$.

[4] R. Otero, F. Rosei y F. Besenbacher. 2006. "Scanning tunneling microscopy manipulation of complex organic molecules on solid surfaces". Annual Review of Physical Chemistry, $57,497$.

[5] EasyScan E-STM, 2004. Version 2.1, Operating instructions, Nanosurf AG, Suiza,

[6] JEOL JSPM-5200 Scanning Probe Microscope. 2003. Instructions, JEOL Ltd., Japón.

[7] Variable Temperature UHV SPM: Benchmarking UHV STM and AFM Technology, Omicron Nanotechnology GmbH, VT UHV SPM 210-V06 Brochure, 2009. <http://www. omicron.de/products/spm/variable_temperature_instruments/vt_stm/media/vt_ stm_1.pdf>.

[8] Low Temperature UHV STM and AFM Technology, Omicron Nanotechnology GmbH, MULTIPROBE LT 260-V03 Brochure, 2008. <http://www.omicron.de/products/spm/ low_temperature_instruments/lt_stm/media/lt_stm_1.pdf>.

[9] I. Horcas, R. Fernández, J. M. Gómez-Rodríguez, J. Colchero, J. Gómez-Herrero y A. M. Baro. 2007. "WSxM: A software for scanning probe microscopy and a tool for nanotechnology". Review of Scientific Instruments, 78, 013705.

[10] HyperChem Release 7.5 for Windows, Molecular Modeling System, Hypercube, Inc., 2002.

[11] W. T. Pong y C. Durkan. 2005. "A review and outlook for an anomaly of scanning tunneling microscopy (STM): Superlattices on graphite". Journal of Physics D: Applied Physics, 38, R329.

[12] J. Xhie, K. Sattler, M. Ge, y N. Venkateswaran. 1993. “Giant and supergiant supergiant lattices on graphite". Physical Review B, 47, 15835.

[13] S. Jasty. 2006. "Introduction to molecular self-assembly". Sigma-Aldrich Material Matters, $1,3$.

[14] A. Ulman. 1991. An introduction to ultrathin organic films from langmuir-blodgett to self-assembly. San Diego: Academic Press, 442 pp.

[15] N. Aratani, A. Takagi, Y. Yanagawa, T. Matsumoto, T. Kawai, Z. S. Yoon, D. Kim, y A. Osuka. 2005. "Giant meso-meso-linked porphyrin arrays of micrometer molecular length and their fabrication". Chemistry - A European Journal, 11, 3389.

[16] G. M. Whitesides, J. P. Mathias, y C. T. Seto. 1991. "Molecular self-assembly and nanochemistry: A chemical strategy for the synthesis of nanostructures". Science, 254, 1312.

[17] A. E. Baber, H. L. Tierney y E. C. H. Sykes. 2010. "Atomic-scale geometry and electronic structure of catalytically important Pd/Au Alloys". ACS Nano, 4, 1637.

[18] H. L. Tierney, A. E. Baber y E. C. H. Sykes, A. Akimov y A. B. Kolomeisky. 2009. “Dynamics of thioether molecular rotors: Effects of surface interactions and chain flexibility". Journal of Physical Chemistry C, 113, 10913. 
[19] J. Matthiesen, S. Wendt, J. Ø. Hansen, G. K. H. Madsen, E. Lira, P. Galliker, E. K. Vestergaard, R. Schaub, E. Lægsgaard, B. Hammer y F. Besenbacher. 2009. “Observation of all the intermediate steps of a chemical reaction on an oxide surface by scanning tunneling microscopy". ACS Nano, 3, 517.

[20] M. F. Crommie, C. P. Lutz, D. M. Eigler y E. J. Heller. 1996. "Quantum interference in 2D atomic-scale structures". Surface Science, 864, 361. 